\title{
Transformations of the Emirati housing typologies A survey on the trending urban condition and cultural clashes
}

\author{
Dr Apostolos KYRIAZIS, Assistant Professor of Architecture, Abu Dhabi University, UAE \\ Dr Magdy IBRAHIM, Associate Professor of Architecture, Abu Dhabi University, UAE \\ Ayesheh BENYAS, Student of Architecture, Abu Dhabi University, UAE \\ Shaikha ALMAZROUEI, Student of Architecture, Abu Dhabi University, UAE
}

\begin{abstract}
It was since the inception of a modernized Abu Dhabi in the late 60s that its housing has been evolving as well. Land allocation to Emirati nationals, the founding of a national housing program and the very new Master Plans for Abu Dhabi were all parts of a major effort of Sheikh Zayed to settle down a primarily nomadic population and provide contemporary amenities and services without compromising their cultural identity. Housing - both individual and social - transformed equally fast to the city itself - from the "Arish" and the "Sha abi" house to the "western villa", thus creating a cultural clash, a paradox between the Islamic-Arabic lifestyle and the imported socio-architectural properties of the villa type. This paradox is strengthened by the environmental behavior of the buildings within the climatic context.

However, it is due to a demand increase and to the latest international socio-economic developments that the current national housing model should reconsider its strategic options in terms of the architectural typologies and the urban footprint used so far. Furthermore, a shift in global urbanism and housing towards open and inclusive cities and against the spatial manifestation of zoning and horizontal sprawl have reopened the agenda on neighborhood densification, housing typologies and a renegotiation of the usage of urban land.

The paper attempts to address the questions regarding this cultural paradox, by highlighting the users' perspective. It presents the findings of a survey amongst Emirati nationals with regards to the compatibility between their cultural daily patterns and their housing. By providing insightful critique on their housing properties and their performance on key notions such as privacy, space, religion, climate, family and car dependency, the respondents assist in depicting their needs. The results of this survey and their interpretation could lead to possible shifts in the housing strategy and policies of the city and the Emirate of Abu Dhabi and potentially to other cities in the Gulf region.
\end{abstract}

\section{Keywords}

Abu Dhabi, housing, typologies, morphology, architecture

\section{Introduction}

\subsection{The Abu Dhabi context}

Abu Dhabi's growth amongst all new cities in the Gulf region is exemplary, reasons being that Abu Dhabi failed to sustain its pre-oil urban core as well as that Abu Dhabi was the last one to embrace modernization (Al Fahim, 2013). Yet, the first step of Abu Dhabi's modernization was arguably the hardest one. Two parameters were key to this observation: first, Sheikh Shakhbout's hesitation to open 
up the city's economy to any foreign intervention that kept the city inactive during the 1960s (Al Fahim, 2013 and Bani Hashim, 2019), a stance that was reversed once Sheikh Zayed took leadership over.

Secondly, any spatial transformation implies a social one. In this regard, Zayed was aware of the necessity to settle the Bedouin nomads down permanently towards the creation of an urban identity, in parallel with a national one (Kyriazis, 2017). Additionally, Abu Dhabi's transformation would require a significant human capital, both the labor force and the service providers. This led to a reshuffling of the population ethnic mix that still characterizes the UAE today1. Sheikh Zayed had anticipated this transition and requested that the new housing schemes for the Emiratis ought to preserve and reflect the local cultural values (Elsheshtawy, 2016).

With regards to the establishment of a national-cultural identity upon the birth of the Emirates' Union in 1971 and a connection to the land (both literally and metaphorically), land distribution acted as motivation and as a catalyst for development. Sheikh Zayed initially gifted three land plots to each Abu Dhabi native - a residential, a commercial and an industrial one - at an unprecedented move (Al Fahim, 2013). Furthermore, he prioritized the replacement of the traditional "arish" (palm frond) housewith the "Sha'abi" (the "people's house"), a modernist adaptation of the Bedouin lifestyle (Elsheshtawy, 2016). It was the beginning of the national housing program (for Emirati nationals), a program that remains highly active to date.

\subsection{Urban Planning Provisions}

The early transformations on housing were endorsed by all Abu Dhabi's master plans, starting from 1962. Given the eradication of its pre-oil core, Abu Dhabi's architecture and urban planning have become a key factor on introducing a novel, modern identity for both the newly-born federal state of the UAE and its Capital city. Doxiadis' superblocks influenced the iron grid plan that also fitted the political priorities for equity, uniformity and flexibility enough to rapidly channel the anticipated oil revenues into the production of urban space (Kyriazis, 2017).

Both the Harris and Halcrow Plans in 1962 proposed attached units organized on L-shaped, courtyard blocks. They were both rejected though for the curved road network proposed, as Zayed preferred a more practical iron grid. The Master Plans of Arabicon, Takahashi and Abdelrahman Makhlouf followed that rigid grid ever since. It was the latter one though that in 1968 proposed a neighborhood module to fill in the Superblocks. A module based on U-shaped clusters of single houses (in single plots) that separated pedestrian and car traffic and provided all amenities within walking distance. Makhlouf mentioned: "I made a social plan for how we would fill Abu Dhabi's grid with housing. Each unit had seven houses. The plan was made so that neighbors from the same block could sit together after evening prayers. My plan reflects their traditions. You don't have to walk far to visit your family, and you had all your services, including the mosque and school, nearby" (Reisz, 2013). However, the "sha'abi" villas he designed and incorporated into his neighborhood modules were destined for Emirati nationals only, as expatriates were expected to live in the CBD apartments (Bani Hashim, 2019).

By the early nineties, the main Abu Dhabi Island gets saturated and development pushes towards the vast mainland. The Comprehensive Plan of 1998 - conducted by Atkins - is the one to introduce the suburbia of low density, extreme zoning and sprawl. Since then, two types of housing provision exist in those areas:

Housing units (and their land plot) that were constructed en masse and distributed to the national program recipients. All those units shared the same design, a hybrid adaptation between the sha'abi plan and the "western villa".

${ }^{1}$ On 2016 , only the $13 \%$ of the UAE population was Emirati nationals. 
Housing units that were designed/constructed under different plans, as the owners were recipients of land plots only. They were annotated as "private villas" (houses for the nationals to live in) and "investment villas" (houses to be rent to expatriates for income generation).

Through the Abu Dhabi 2030 Framework Plan (issued in 2007) the city would upgrade from a federal capital to a global hub in tourism, sports and culture through an emphasis to leisure and "starchitecture". Urbanisms of exclusion (Kyriazis, 2019) were created along the seashore, while the suburbs kept on expanding horizontally.

The 2030 Plan also allowed for free and unbiased expression of architectural styles. Indeed, the influence of the Sha'abi house as a social and typological transition, the ethnic diversity of the architects in the country and the lack of of criticism on the accessibility to easy, popular architecture, has led to a polyphony of architecture morphologies within the already featureless suburbs (Kyriazis et al., 2018).

\subsection{Housing Transformations}

As the city was evolving, the housing unit types were evolving as well. However, those transformations seem to follow three distinct resonates that still define the urbanscape. The early transformation attempts from the fareej to the sha'abi house were accepted by the locals with skepticism, as the rigid modern layouts and the shared courtyards were not reflecting their cultural particularities (Elsheshtawy, 2016). However, improved versions of the sha'abi house made the Emiratis customize spaces and adapt easier to the new, civic life (Elsheshtawy, 2016). Furthermore, according to Stanek (2020), Makhlouf's master plan and the Sha'abi houses consisted the manifestation of a cracking point between technological modernity and cultural (Arabic-Islamic) specificity.

The second shift (from the courtyard house to the detached villa) had paramount implications on the production of urban space, sprawl, the human scale and the sociocultural daily patterns and behavior (Kyriazis, 2018), albeit with limited literature. Menoret (2014) argues that the first villas were implemented to host the western expatriate officials of ARAMCO in Saudi Arabia, soon after the beginning of the oil boom. The detached villa became a trend, an icon, a means of splurge and a tool for social segregation and gentrification from within.

The western villa transition in Abu Dhabi took place within the early 80's. All developments including the national housing program were increasing plot sizes and automobile dependency to the expense of community facilities (Alawadi, 2018). Combined with new sets of standards by authorities and the need of the land-owning nationals to distinguish themselves, the villa typology prevailed and monopolized all low-rise areas of Abu Dhabi.

The third housing transformation was an outcome of the increase in both the demand and the push for larger profit margins through the intensification of the plot use (Bani Hashim, 2019). Under a series of increases on development control regulations (maximum heights, GFA, plot coverage and the like), more properties were allowed to become investment ones (through subdivision) and increase in floors and total area, thus significantly altering the urban scale properties of entire neighborhoods (Kyriazis et al., 2018).

A fourth transformation would be the return to the "fareej", the Arabic neighborhood, and the courtyard house as its single unit. On one of its manuals, the Abu Dhabi Urban Planning Council called designers and developers to openly consider returning their housing projects back to the courtyard house model and the multiple virtues of the organic and compact Arabic urbanism (UPC, 2007). The "fareej" would be an opportunity to reuse traditional ideas under contemporary technologies. 


\section{The Survey}

\subsection{Research Question - Methodology}

The focal point of this paper remains on the housing transformations and extends the initial question that Kyriazis (2018) refers to: Sociocultural daily patterns as well as the existing climatic condition seem to contradict the reasoning of the second housing transformation (from the courtyard house to the detached villa) and fail to justify the dominance of the existing housing morphologies and architectural vocabulary. This paradox, as viewed from the housing users, remains the subject of the research presented here. How do Emirati nationals experience this contradiction between their cultural needs and the very house they dwell in? Is there a balance between the overall given context and the act of living and how dynamic is it?

A survey was used, in order to shed light to the users' perspective. It was addressed to Emirati nationals only as they are the only ones to have an opinion regarding the full range of available housing in the city (that would include all typologies and usage types, from apartments and private villas to the national housing program settlements. The survey revolved around two main questions-issues. First, the inquiry on the relationship between the respondents' cultural habits to the architecture of their houses. Second, to identify current trends and shifts on Emiratis' preference of housing types that could allow urban planners to consider densification options for the existing suburban zones at an attempt to control and reverse the urban sprawl and increase the functionality and sustainability parameters at the neighborhood scale. Lastly, the survey attempts to highlight the need to address issues related to contextuality, locality and a synthesis-driven design, thus reiterating the importance of architectural design.

\subsection{Identity of the Survey}

The survey was conducted digitally through the "survey monkey" digital platform for five months (from March to July 2020). A total of 227 replies were received with a completion rate of $78 \%$ (177 complete and 50 incomplete replies). Out of them, 140 replies (61.67\%) belonged to women and $87(38.33 \%)$ to men. The majority of the respondents (151 or $66.52 \%$ ) were at the younger end of the age frame (18-30 years old), with the ages of 30 to 50 years old to follow (73 individuals or $32.16 \%$ ) and only three people above 50 years old (1.32\%). This distribution is indicative of the dynamic status of the Emirati nationals' population. Out of the overall participants, 140 (61.67\%) were not married and only 87 (38.33\%) of them were married (figure 1).

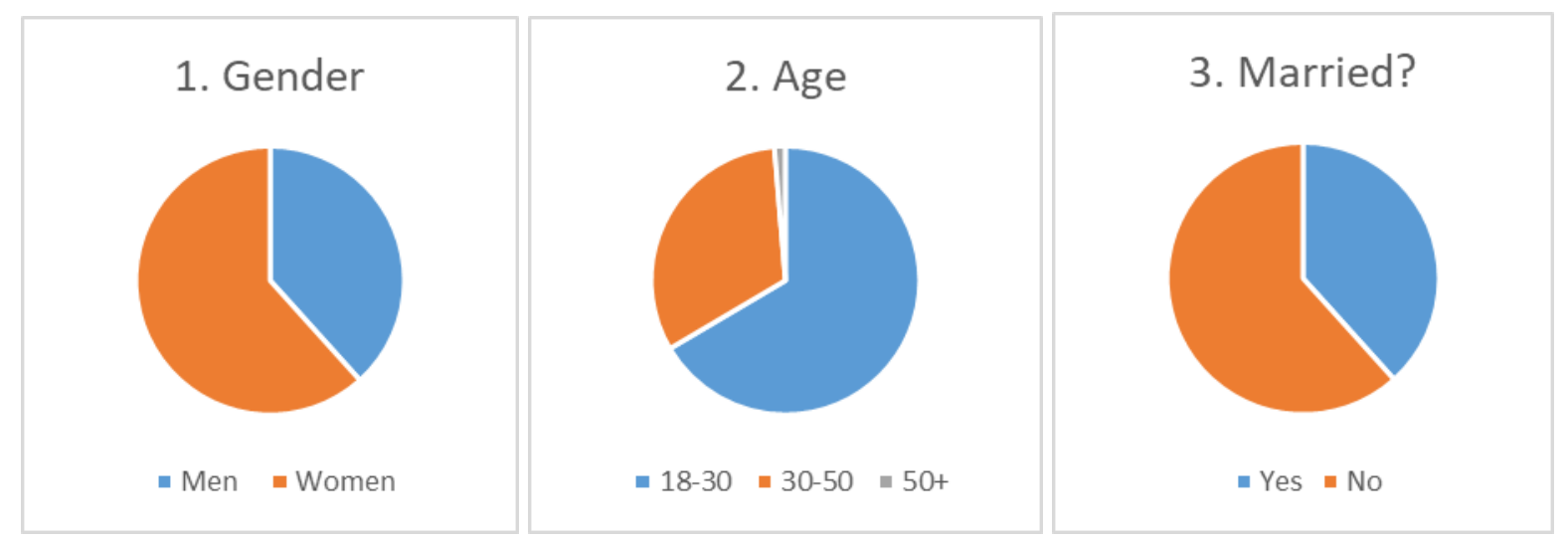

Figure 1: Questions 1 to 3 (Personal Information).

\subsection{General Housing Information}

The second chapter of the survey was seeking information on the main housing properties. 
In question 4, the $76.67 \%$ of respondents own the house they live in. The ownership occupancy percentage was expected to be higher due to the UAE particularities (the Emiratis-only land ownership, loan payments' facilitation etc.) (figure 2). In support to those answers comes the response to ownership of other housing units in Abu Dhabi (question 5): A significant part (78.57\%) of respondents do not own other houses in the Emirate. (figure 2). Therefore, despite the fact that Emiratis enjoy favorable conditions within the real estate market of the country for owning both land and housing, the ownership occupancy percentage remains in rational levels. This may also be affected by two more elements: First, by Emiratis that may dwell in housing that is provided by their employers. Second by the fact that housing subdivision and lease to other residents was allowed in several districts of Abu Dhabi.

The financial robustness of the indigenous population shows on the fact that only a $29.05 \%$ of them live in a house that was provided by the National Housing Programs, while a $70.95 \%$ of them do not (question 6). While it would be extremely important to view the dynamics of this distribution and its evolution through time, this majority of $71 \%$ could also be broken down to factors that ought to be highlighted (figure 2).

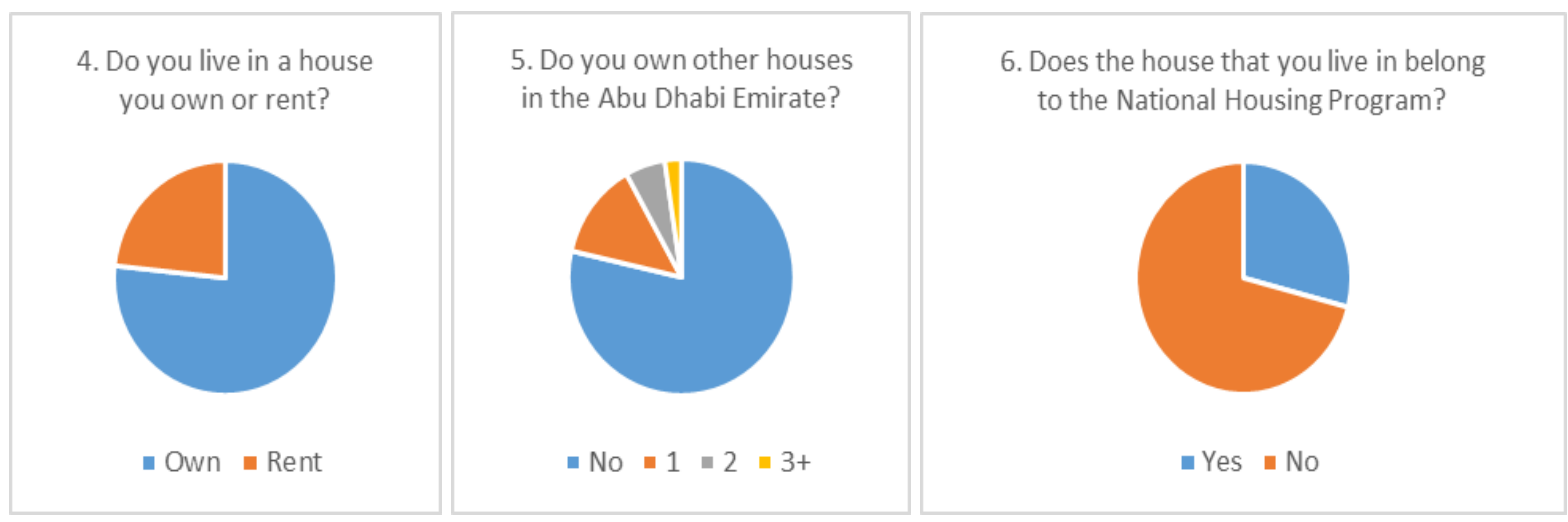

Figure 2: Questions 4 to 6 (House Ownership)

Question 7 asks on the age of the house that the respondents are living in. Remarkably enough, the percentage decreases with the building stock ageing. The majority of houses inhabited by the respondents are built after 2000: A 34.45\% of the total in the 2000-2010 decade and a 34.93\% after 2010 . This linear distribution is also indicative of the overall improved quality of Abu Dhabi's housing stock (figure 3).

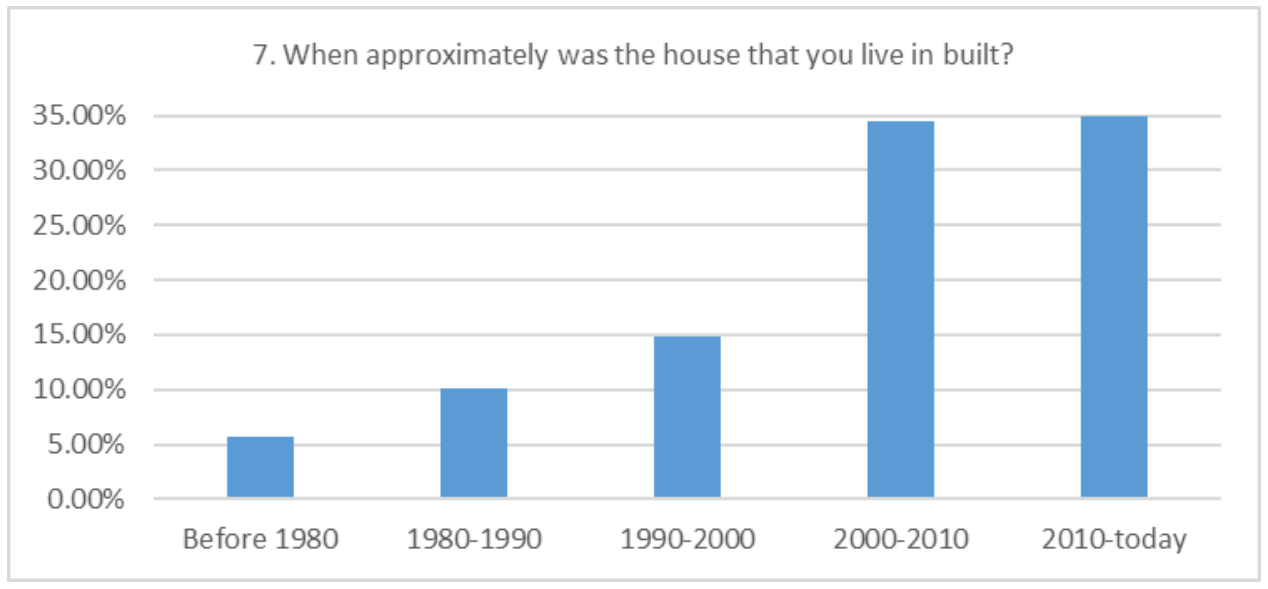

Figure 3: Question 7 (Building stock age)

The size of the households is another critical issue.In 210 responses on question 8 , an average of 9.83 people per household came up, significantly higher than the average values on the Abu Dhabi 2030 Framework Plan (ADUPC, 2007): 9.5 people per household on rural areas, 8.1 for Al Ain and the Western 
Region and 7.6 for Abu Dhabi. The most common responses were: five and eight people ( 25 times each) and ten people (22 times). In terms of clusters, the 5-10 people per household group stands out with $54.7 \%$ of the total responses. A $33.8 \%$ of the responses contains numbers higher than the 10 people average. This is a remarkable part of the households, for which special architecture solutions that could accommodate large numbers of individuals must apply. If combined with the strong findings of question 5 , it could raise an issue of a shrinking financial status within families or their inability to purchase additional housing and claim independence (figure 4).

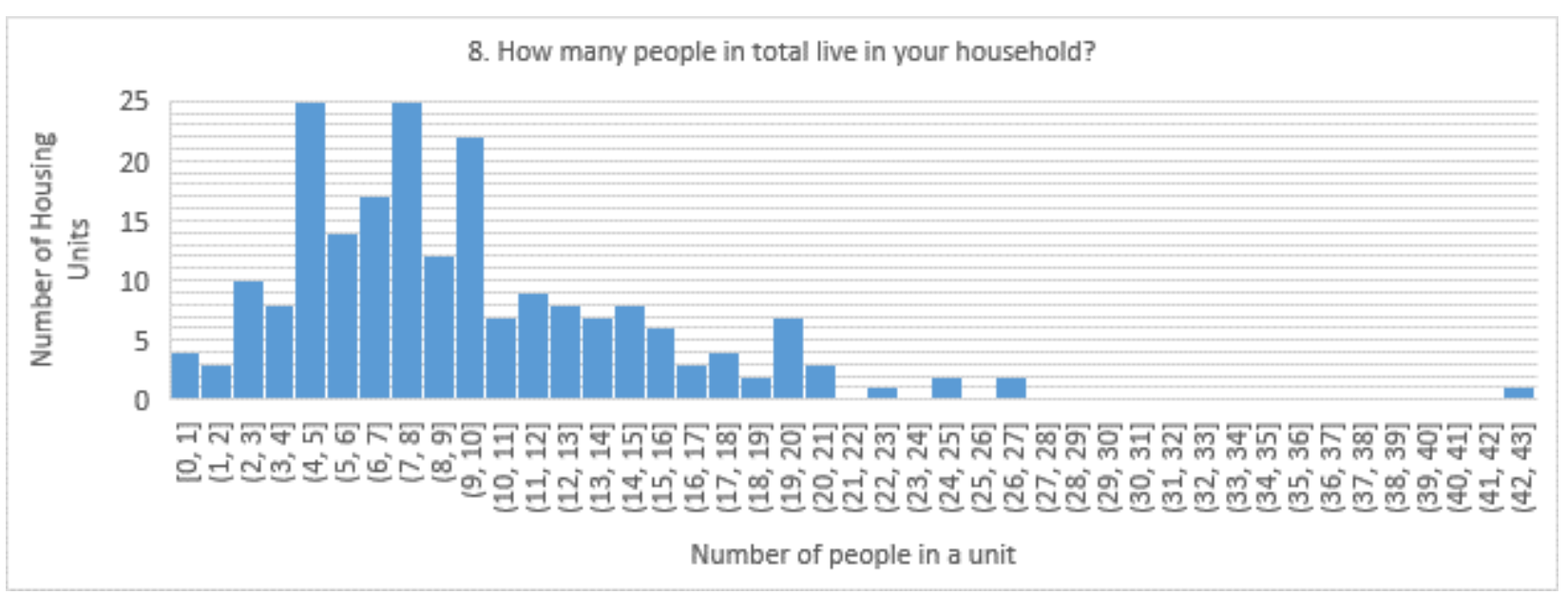

Figure 4: Question 8 (people per household)

Typologies are also mentioned in the following question (question 9): A $57.62 \%$ of the respondents describes their house as a "courtyard house" (figure 5). Overall, it seems that the participants are happy with the house they live in (question 10 ). A $68.57 \%$ claims happiness, while only an $18.1 \%$ suggests the opposite (figure 5).

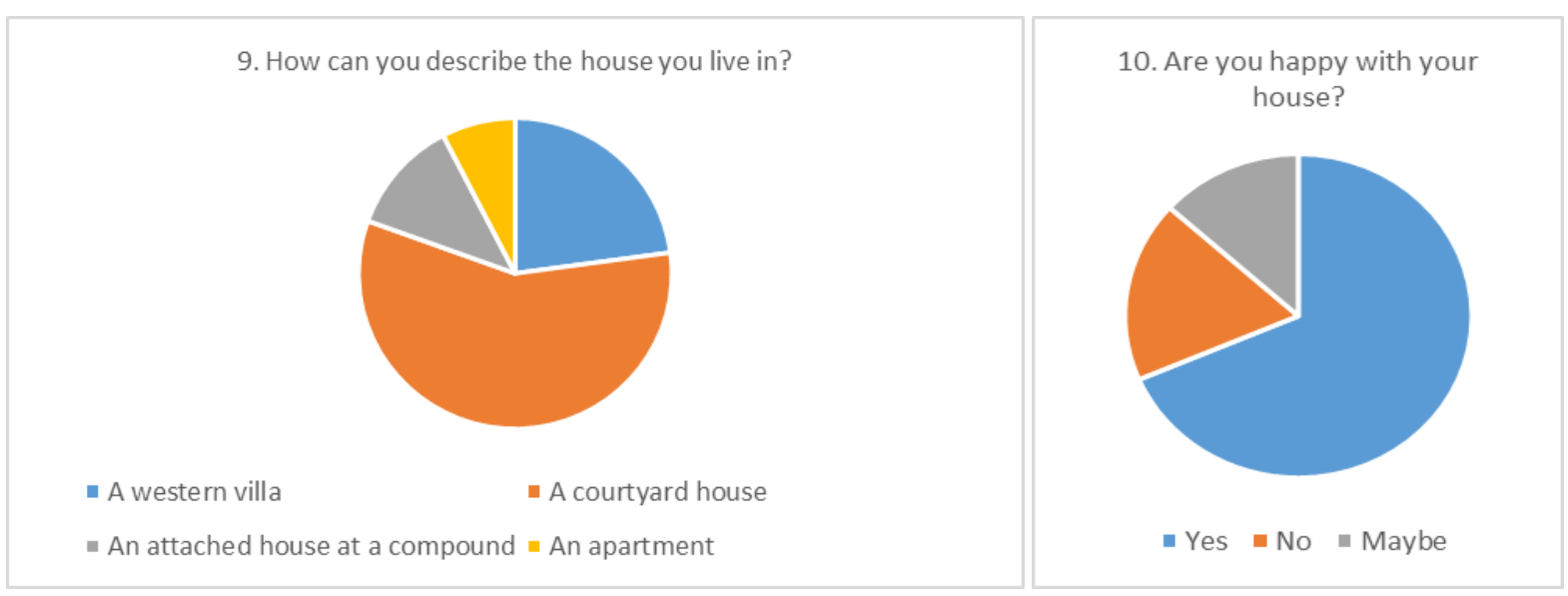

Figure 5: Questions 9 and 10 (main description)

\subsection{Morphology - Typology}

The third chapter of the survey is dedicated to more specific morphological features and typological properties.

As it appears on question 11, a $65.14 \%$ of the respondents live in a house with a garden, while a remaining $34.86 \%$ do not (figure 6). However, if compared to question 9 and the $7.62 \%$ apartment occupancy, one could argue for the lack of gardens within the other mentioned typologies (especially the attached housing). 
Question 12 is deepening the No11 one. The majority of the participants $(31.52 \%)$ admitted that they never use their garden, while an equally remarkable part (28.48\%) uses the garden at a seasonal basis - a finding supported by the extreme climatic conditions during the summer (figure 6The apparent behavioral inconsistency between the answers in questions 11 and 12 can be justified by - as aforementioned - the climatic conditions, namely the constantly extreme heat and humidity levels from early May to October. However, privacy also contributes to this finding (Kyriazis et al., 2018).

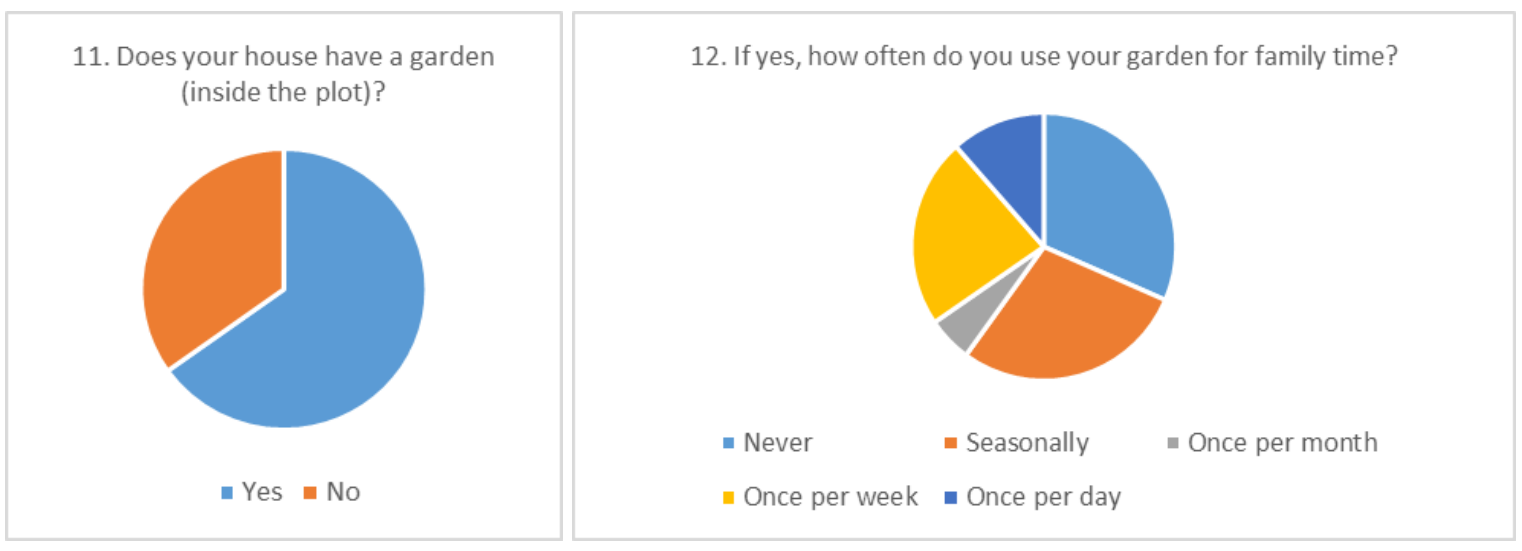

Figure 6: Questions 11 and 12 (garden)

Questions 13 and 14 attempt to elaborate on the qualities of the open plot space and highlight the dimension of automobile dependency in the city. Despite the fact that the majority of Abu Dhabi's streetscape is spacious enough to accommodate on-street parking for plot owners and visitors alike, the majority of the housing plots contain at least one car parking spot. Regarding this particular survey, 8 out of 10 plots do (question 13). In particular, a 37\% of such in-plot car parking areas actually occupy parts of greenery. Comparing though the total number of respondents to question 14 to the ones that replied "yes" on question 13 can safely push that last response to roughly 50\% (figure 7).

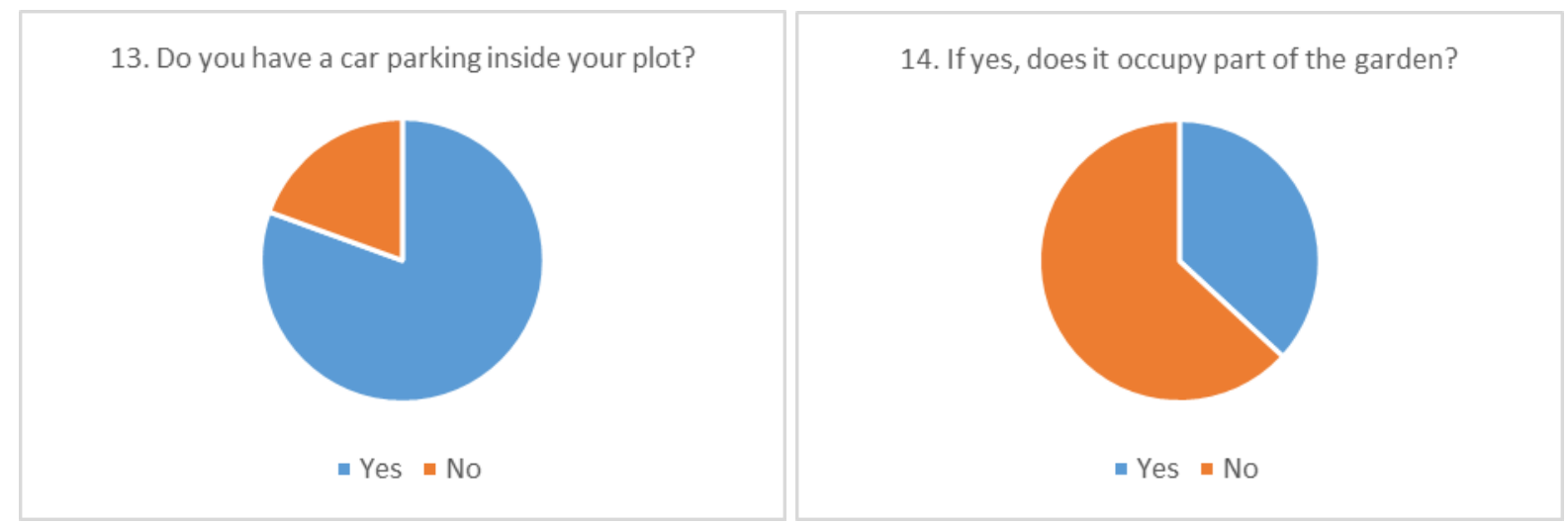

Figure 7: Questions 13 and 14 (car parking)

Question 15 is trying to shed light into the qualities of the plot's open space and to the desires of its users (figure 8). Surprisingly, the smallest fraction of the respondents requests for more car parking space into their garden. Privacy in the other hand can mostly be related to the urban design properties at the neighborhood scale. Depending on the buildings' heights and the built/open areas dimensions and ratio, some more conservative families would hesitate using their garden space in order to avoid visual contact from their neighbors' upper floor windows. This behavior could explain the question 12 findings. 


\section{What would you prefer for your garden?}

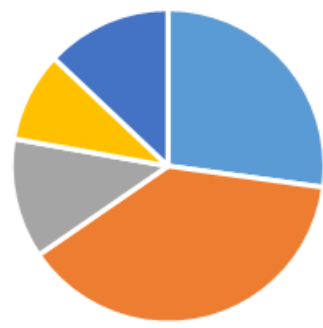

- More privacy - More greenery " More play area " More car parking space - More shadow

Figure 8: Question 15 (garden)

Questions 16 and 17 ask about the house itself, as a bulk size. The numerical options chosen by the researchers had to adapt to the large size of the housing units. Since this study focuses on Emirati nationals, it is both their demographic needs (UPC Manual) and the historical evolution of their housing properties (Alawadi, 2018; Elsheshtawy, 2018; Kyriazis et al., 2018) that led to such numbers. According to that choice, $37 \%$ of the respondents live in a house of $120-200 \mathrm{~m}^{2}$ in area (net floor area), $23 \%$ of them in a house of $200-400 \mathrm{~m}^{2}, 22 \%$ in a house less than $120 \mathrm{~m}^{2}$ big and a remarkable $17 \%$ in a house larger than $400 \mathrm{~m}^{2}$ in size. Those findings are not surprising. Both the individual housing units ("western" or stand-alone villas) and the ones provided by the national housing programs usually exceed $200 \mathrm{~m}^{2}$ of GFA (gross floor area). Surprisingly, a 39\% of the respondents stated that they could use even more space and contrasting to that, only $2 \%$ could live with less than what they have (question 17 , figure 9 ).

When the same question was posed regarding the overall land plot size, a small but indicative shift was observed (figure 9). According to this, the respondents that could live on an even smaller plot reduced to just $1 \%$ and the ones that could ask for more space increased by $3 \%$ (to $41 \%$ of the total).

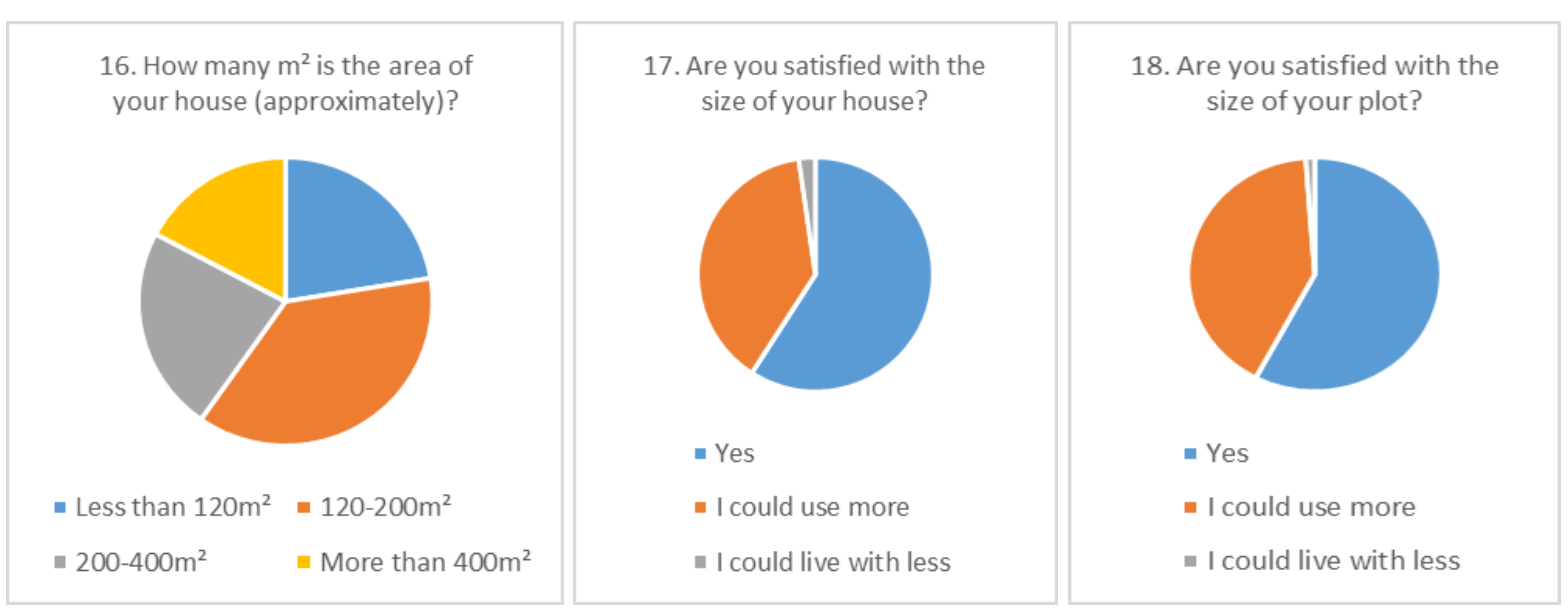

Figure 9: Questions 16 to 18 (house and plot sizes)

Questions 19-24 pass on a subject more related to typologies and the experience-usage, yet still interrelated to the overall morphology of the housing unit and the neighborhood.

While the extreme climatic conditions heavily affect behavioral and usage patterns on housing, the interior spaces do not necessarily follow. On the question related to the usage of air conditioning (19), a remarkable $61 \%$ of the respondents admitted that they keep the $A / C$ units on throughout the day, every day, on every season of the year. The consequences of this finding are severe with potential impact on the physical health of the inhabitants, on the waste of electricity and on the prolongation of heat-island effects at the neighborhood scale (figure 10). 


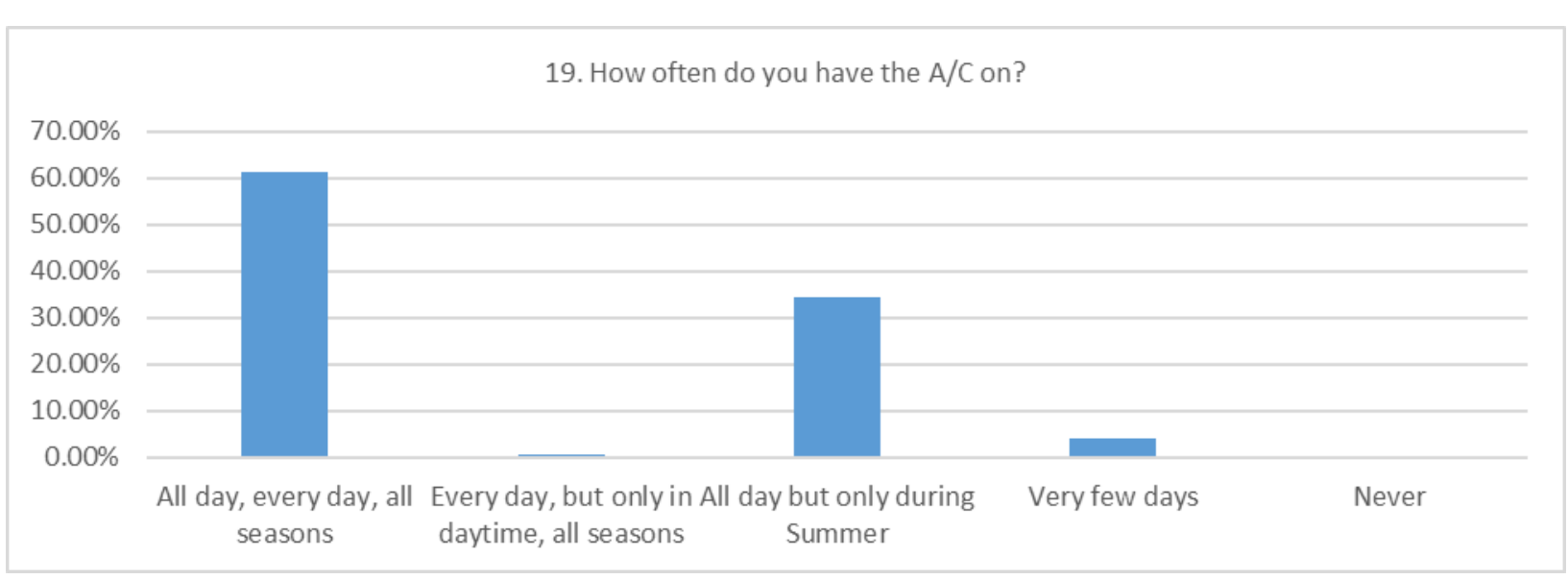

Figure 10: Question 19 (Air Conditioning)

Question 20 raises the issue of the existence of big floor-to-ceiling windows in major spaces of the house (i.e. the living room) and the respondents' majority replies affirmatively (52\%). This is an expected result, also supported by the findings of Kyriazis (2018): house owners seem to have preferred an imported façade typology that is associated with the creation of style and image that consequently generates social status rather than resonance and adaptation to local conditions.

Question 20 also attempts an introduction and connection to the topic of privacy, as one of major importance for sociocultural reasons. The existence of large glass surfaces may be associated with a depreciation of privacy in the hierarchy of design principles and the findings of question 20 could suggest such a transition. However, the following question (21) seems to overturn this impression. In particular, when questioned how often do people keep the curtains open in their main windows. A $17 \%$ replied "all day, every day" and a prevailing $65 \%$ replied "every day but only during daytime". Those two combined at $82 \%$, indicating a turn towards a more rationalized privacy management within the house. At the same time though, they also underline the paradox of having large curtain-wall facades but disregarding the consequences on indoor heating and an increased energy consumption.

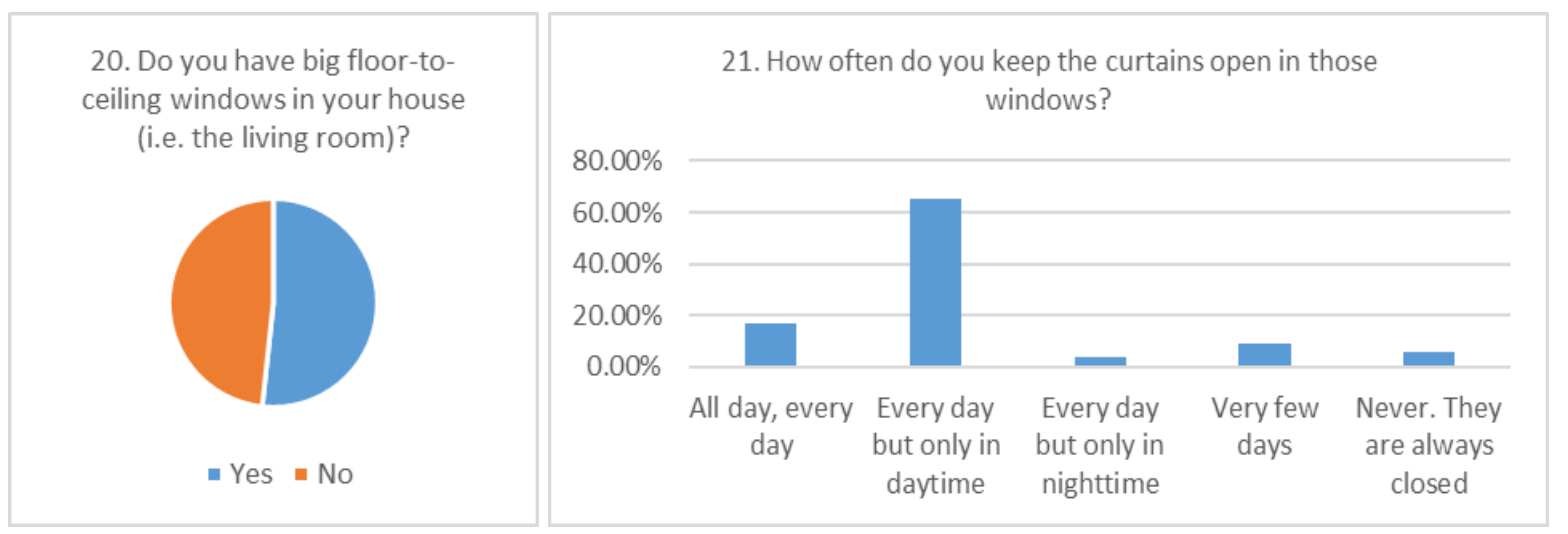

Figure 11: Questions 20 and 21 (Windows, curtains)

Question 22 directly poses the issue of privacy within the housing units of the respondents. Remarkably, a significant $44.57 \%$ does feel exposed in some areas of their house. Details on those areas surface with the help of question 23. Out of the 75 replies, there were several cases with more than one spaces reported. In total, bedrooms topped with $37.3 \%$, followed by living rooms $(27.7 \%)$ and two outdoor spaces, the front yard (9.6\%) and the back yard (8.4\%). The prevalence of living rooms and bedrooms combined with the findings of question 21 could raise an issue of privacy concerns, according to which, the tenants' preferences do not match the architectural solutions of their own houses. This hypothesis needs more documentation and support, yet indicates a possible gap of knowledge and understanding of 
the purpose that different architecture typologies, morphologies, elements, materials and solutions serve. An alternative explanation would be the fact that - as shown in question 4 - one out of five respondents do not own the housing unit they live in and therefore have not contributed to its design at any way.

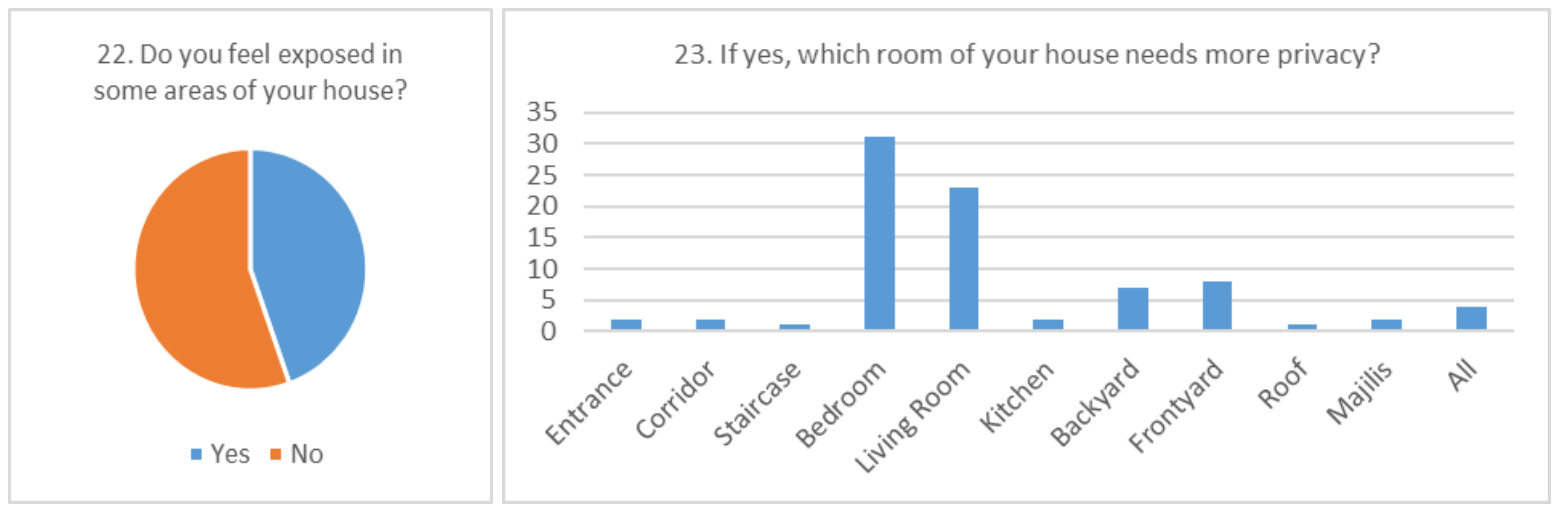

Figure 12: Questions 22 and 23 (privacy)

Questions 24 and 25 attempt to deepen on this issue and combine its findings with the ones of question 16 and potentially 17 . According to them, a $26.55 \%$ of the respondents report unused rooms in their house. The numbers stated vary from one to ten (question 25) in inverse proportions (one room for the $36.5 \%$, two rooms for the $25 \%$ and three rooms for the $19.2 \%$ of the cases being the most common). While empty rooms may be expected in large sized houses, they also display the lack of flexibility that both detached and attached single villas has in terms of adapting to the population needs of the residing family (opposed to the sha'abi and the courtyard houses), as it needs to abide to specific volumetric guidelines provided by the municipality codes (i.e. maximum height, maximum GFA, setbacks etc.) (figure 13).

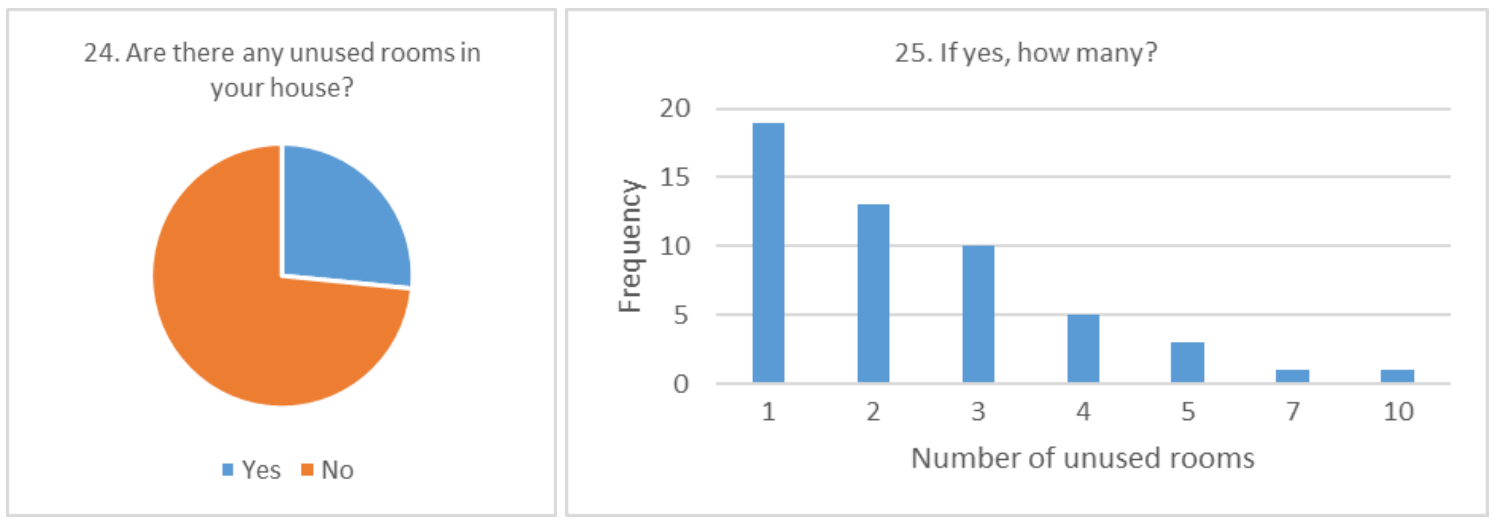

Figure 13: Questions 24 and 25 (unused rooms)

Question 26 therefore becomes an introduction to the courtyard morphology. Together with questions 27, 28 and 36 they attempt to shed light on people's understanding of the term "courtyard" and its social, spatial and sustainability properties. On it, a $74 \%$ claims that they have lived or visited a courtyard house, therefore acquiring some kind of knowledge or experience of it (figure 14). 


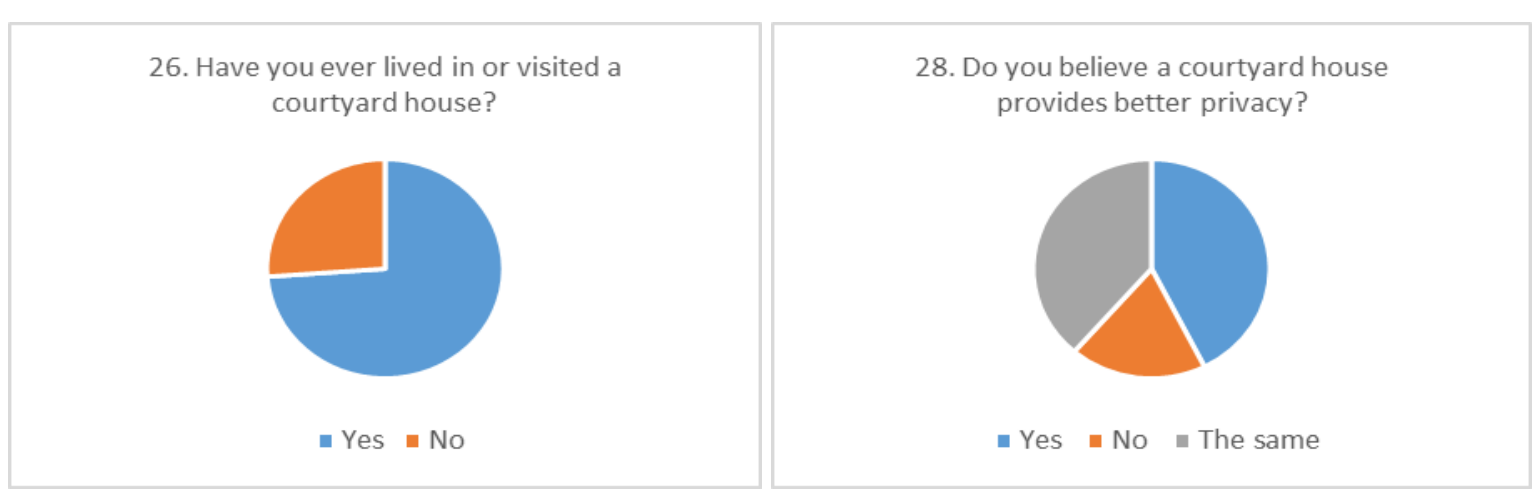

Figure 14: Questions 26 and 28 (courtyards and privacy)

Question 27 asks for details on the courtyard likeability and a reasoning for that (figure 15). Out of the 129 people that responded, ten replied negatively (they didn't like the courtyard) while five others remained indecisive and in a case unfamiliar with the notion of the courtyard. The remaining 114 people (88.4\%) responded positively. Out of those positive ones, only half of them justify their response (as requested) with the elements of added space, comfort, privacy, family gatherings, greenery and children play area being the most popular ones (in order of preference).

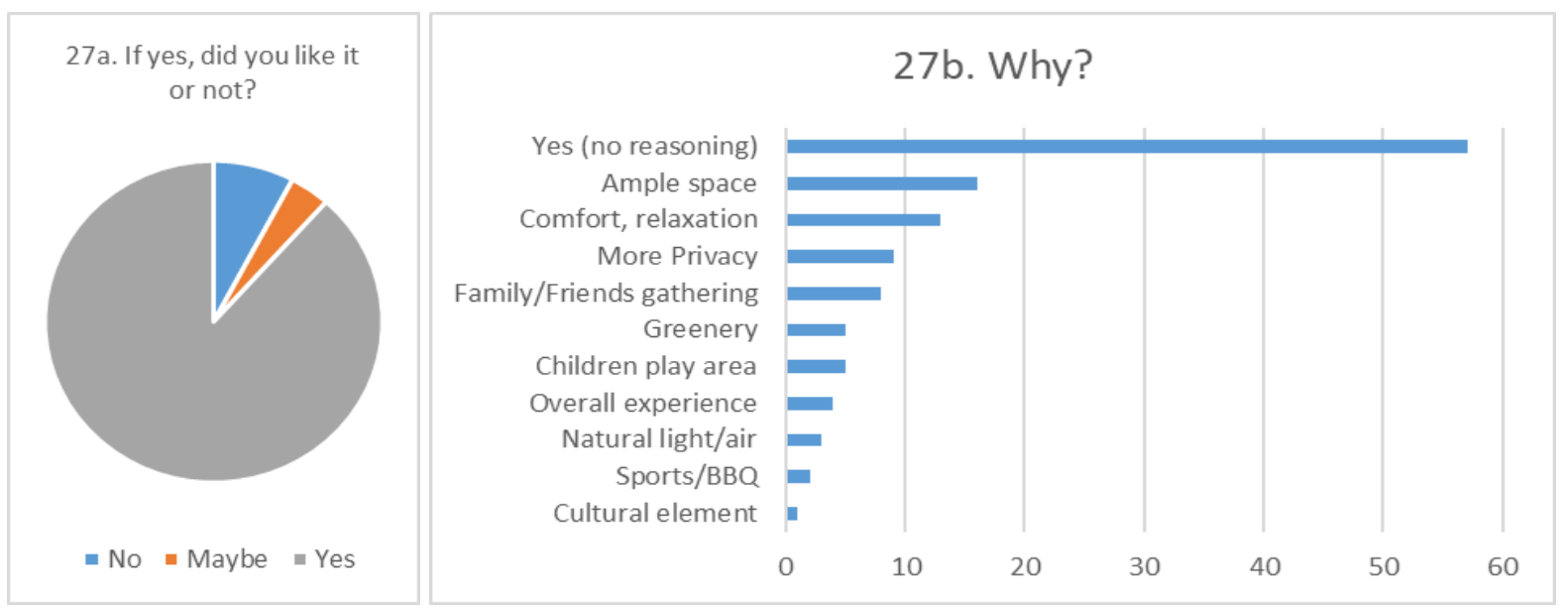

Figure 15: Question 27 (courtyard house)

Question 28 attempts the first direct comparison between different housing morphologies and typologies. The survey showed that a $42.6 \%$ of the respondents believes that a courtyard house provides better privacy than a "western villa" house, while only a $18.75 \%$ believes the opposite(figure 14). While the answers' order seems expected, this almost one out of five fraction that favors the western villa in terms of privacy issues may be characterized as alarming. However, it can be justified by the prevalence of the western villa during the last four decades in Abu Dhabi and the consequent familiarity of the young Emirati population with this particular type alone.

Questions 29 to 33 can be considered as the most anticipated ones, as they would shed light to the current degree of familiarity, likeness and attraction to typologies that were never even brought for consideration to the local population. From the arish house to the "western villa", each household had their own land plot in which they developed their housing in expansion stages. Modernization only solemnized and rationalized the land acquisition. This is also one of the reasons why the national housing program of the UAE has never abandoned the "single house in a single land plot" principle, and all attempts to discuss the possibility for alternative typologies such as townhouses or block apartments have been rejected. 
Fully aligned with the aforementioned thesis, questions 29, 31 and 33 verify the unwillingness of the Emirati population to relinquish the direct connection of their house to their land (regardless of its usability and its use mode). Particularly, in question 29 , a $58.2 \%$ would not consider living in a townhouse (ground and first floor attached housing with front/back gardens). Interestingly, the lack of privacy and interior space were the main reasons for that denial, as highlighted by the open question 30 . Five of the replies also refer to the Arab traditions that are lost and three refer to noise from the neighbors due to the shared walls (figure 16).

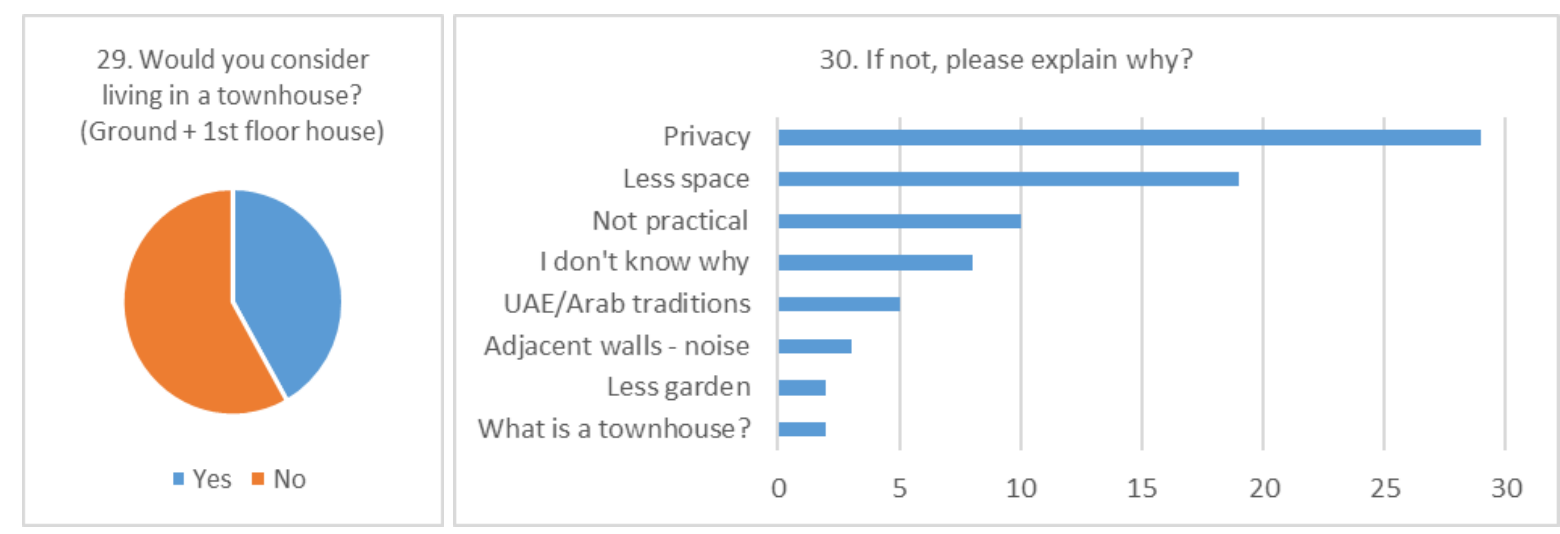

Figure 16: Questions 29 and 30 (townhouse)

If the option of moving to a townhouse seemed relatively fair (to the remaining $41 \%$ of the respondents), the option of a building apartment (with common garden and facilities) appears to be even more distant and undebatable. On question 31 , only $10.9 \%$ of the respondents would entertain the idea, while a majority of $89.1 \%$ would not. When asked for justification of this denial, most of them referred to privacy issues, with the less indoor and less outdoor space replies following (figure 17).

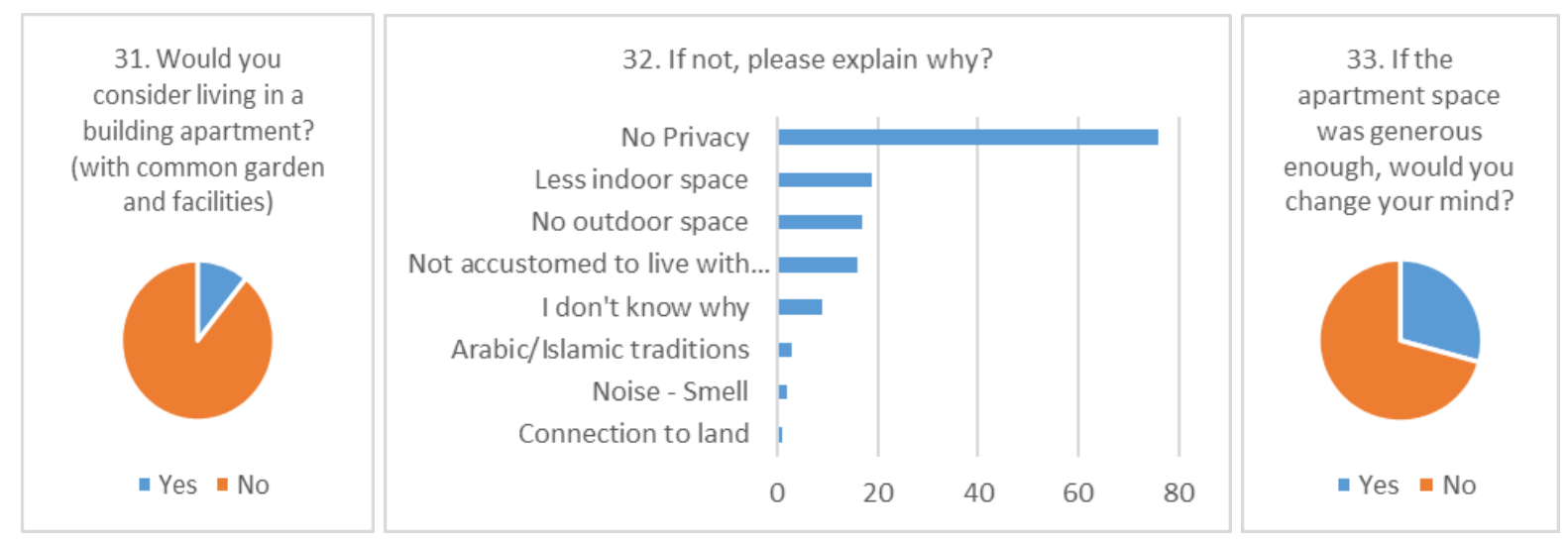

Figure 17: Questions 31 to 33 (apartments)

However, on question 33 , the robustly negative response aforementioned was partially blunted as a $29.3 \%$ would consider moving to a spacious apartment (a significant raise from the previous $10.9 \%$ ), yet a remaining $70.7 \%$ would not give in (figure 17 ).

In the questions that follow and close the survey, questions 34,35 and 37 attempt to identify a connection between morphology, materiality and the response to the climatic conditions. However, questions 36, 38 and 39 turn their focus on an aesthetic and cultural connection instead. This shift was intentional, as questions 35 and 36 were accompanied by images of typical housing), thus aiding the participants.

In question 34 , the majority ( $85.1 \%$ ) of the respondents are aware of the fact that the form, positioning and materiality of a house can affect its heating and cooling(figure 18). 
34. Do you know that the form/positioning/materials of the house can affect its heating and cooling?

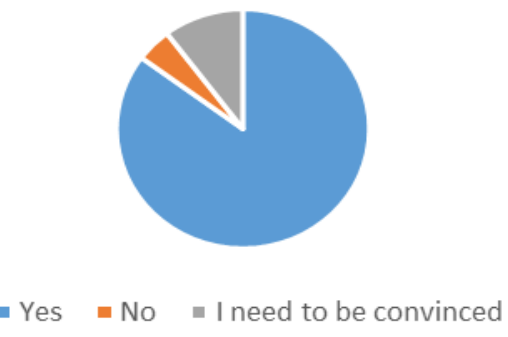

Figure 18: Question 34 (design and climatic performance)

Question 35 provides a visual assistance to the respondents, on their attempt to identify the courtyard houses. It may also partially verify the findings of question 9 and the level of understanding of the basic morphology and typology features. A total of $77.5 \%$ picked up the correct "courtyard" houses (two out of the five options provided). (figures 19 and 5).

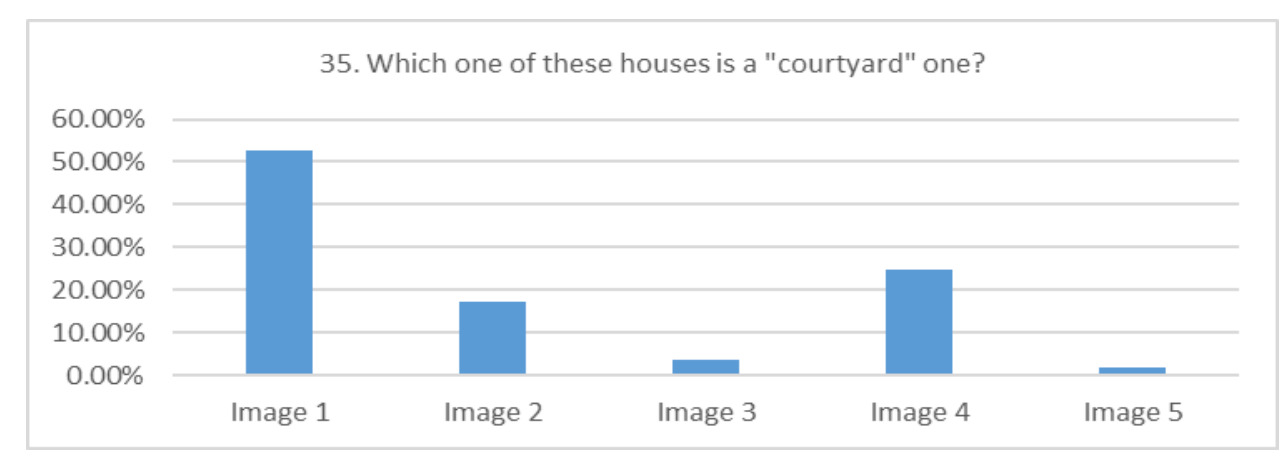

Figure 19: Question 35 (Courtyard house selection)

Question 36 uses an imagery support as well, this time from contemporary housing cases in the region, asking for people's preference on their most likeable and desirable villa. Despite the fact that answering would imply a call on subjective aesthetics, it could also provide an insight on the imaginary, a sneak peek on a speculated connection between the image of the house and the social status. Indeed, the second and third selected options (of $34.7 \%$ and $11.4 \%$ respectively) show excessively luxurious single houses. Interestingly, the most selected option (45.5\%) belongs to a newly designed and built single house with minimal architectural elements and ample open plot space. However, opposed to that, an option showing a new villa of similar architectural principles did not receive people's choice ( $2.8 \%$ of the total), possibly due to the lack of surrounding greenery. Lastly, a house that follows a novel and dynamic approach of the courtyard morphology and a group of townhouses with contemporary hues of vernacular elements also receive a low number of replies (figure 20). 


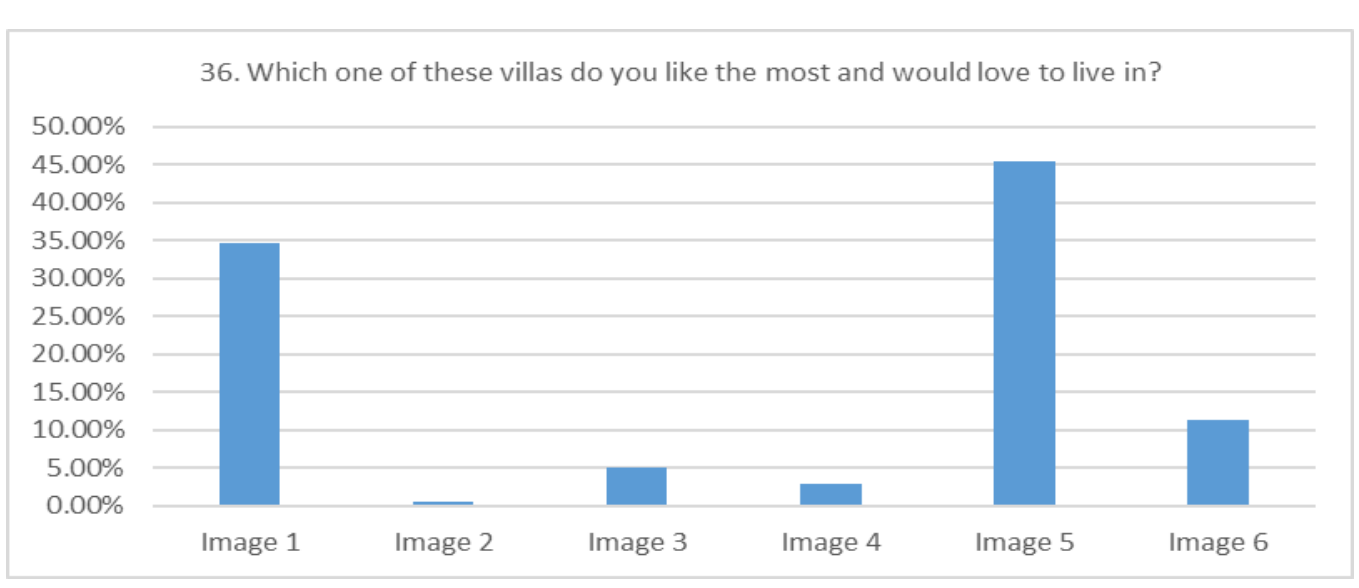

Figure 20: Question 36 (favourite villa)

In questions 37, 38 and 39, the respondents are called to "grade" the four main housing types that are met in the Abu Dhabi Emirate in terms of their response to the UAE climatic conditions, to the cultural practices and to the overall UAE culture. In question 37, the courtyard house prevails (73.9\%) as the type that better fits the local climate conditions. The surprise though comes from the almost no-vote for the attached townhouses and apartments (figure 21).

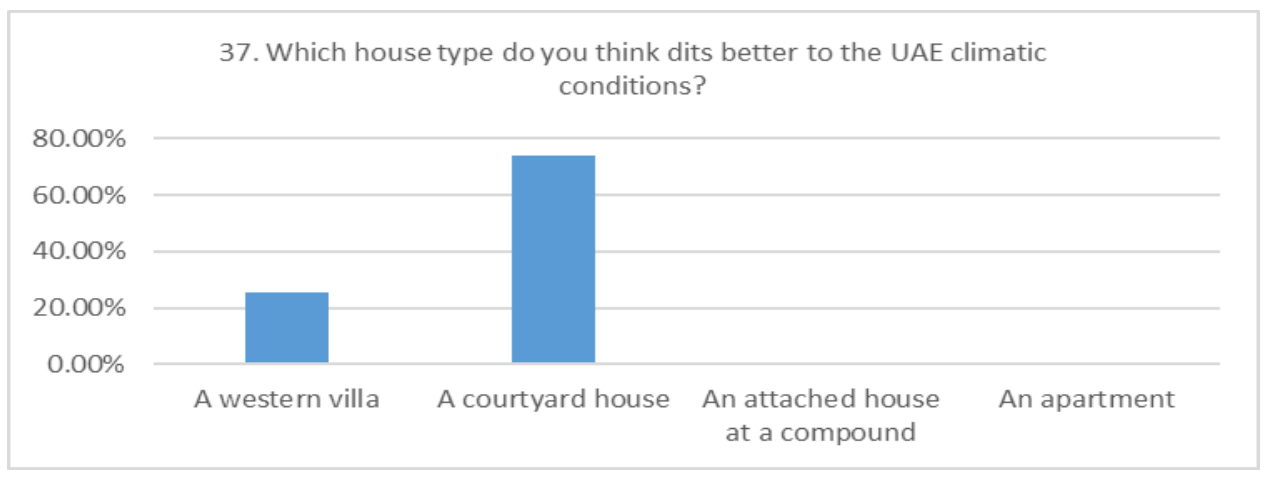

Figure 21: Question 37 (house type and UAE climate)

The same set of options is provided in question 38, regarding the level of service to the respondents' cultural practices (including religious rituals). The responses were similar to the previous one. Remarkably, similarity remains on the last question of the survey, in which culture is narrowed down to a national level (UAE), with only a slight raise on the dominance of the courtyard house (to almost $79 \%$ ). Furthermore, this observation indicates a concurrence between the UAE culture and the overall cultural practices that include religion (figure 22).

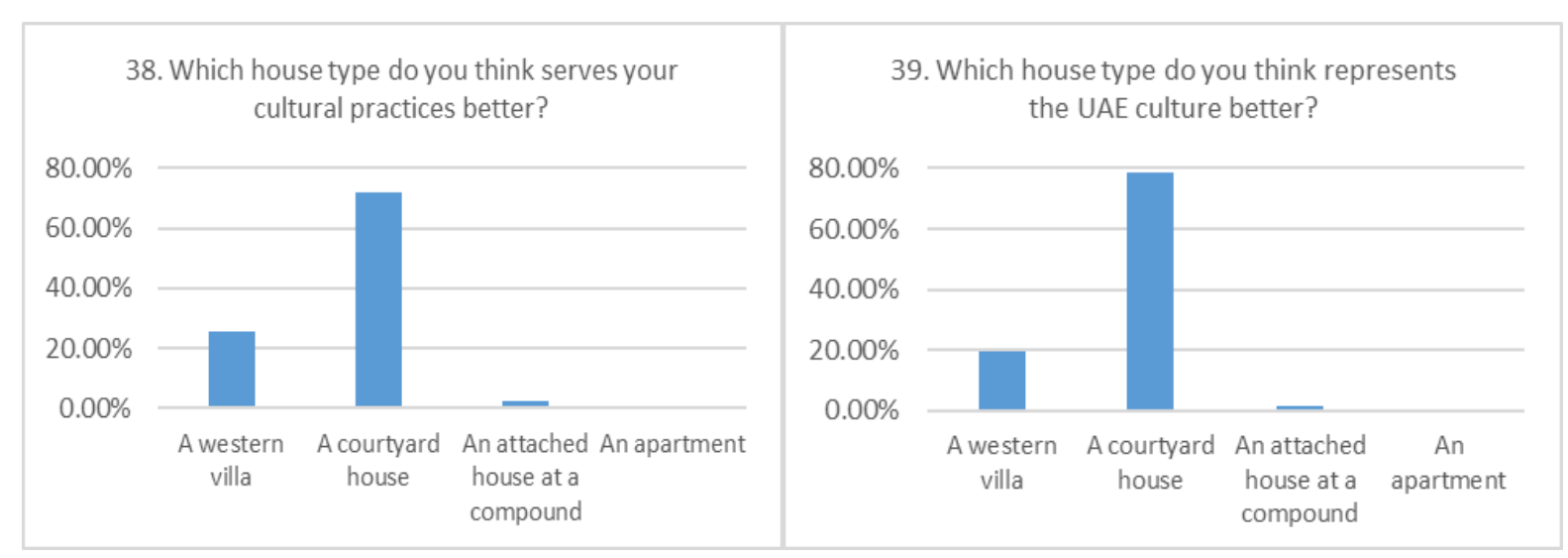

Figure 22: Questions 38 and 39 (house type and culture) 


\section{Interpreting the Survey}

Following the original hypothesis, the survey revealed several interesting results, likethe relatively high percentage of Emiratis that stay on rent, the equally high household size (with a high cluster on 5-10 people and an average that exceeds the official one used on the Framework Plan 2030) as well as the young age of the housing building stock. The majority of the respondents claim that they live at a courtyard house, despite the fact that few courtyard houses actually remain in Abu Dhabi,

Car dependency in Abu Dhabi has infiltrated the private plots, as in most cases - apart from the on-street parking spots - cars occupy most of the plots' open areas. However, people acknowledge this issue, asking for more greenery/play area and more privacy instead. Four out of ten ask for more plot area as well as for an increased house area (GFA), despite the fact that contemporary houses of the national program can reach a $400 \mathrm{~m}^{2}$ to $600 \mathrm{~m}^{2}$ gross area.

More than half of the houses have big floor-to-ceiling windows on their main rooms - a finding that supports observation (Kyriazis et al., 2018) and verifies the hypothesized switch from a practical architecture of special climatic and cultural conditions and scarce resources to a popular architecture for the pursuit of a social imagery. Unsurprisingly, $60 \%$ of the respondents stated that they keep the $A / C$ units on all day, every day for all seasons, a choice that is generated by the poor response of the building to the local condition.

The centralized positioning of the western villa within its plot comes with a set of consequences related to both the management of the climatic response and privacy. Curtain wall facades and a surrounding garden (that is visually exposed to adjacent villas) consist a privacy breach, as half of the respondents feel exposed in their houses and in particular the bedroom, the living room and the garden (in general). A similar $42.6 \%$ believe that a courtyard house provides better privacy. Furthermore, courtyard houses better represent both the UAE culture and the overall cultural-religious practices better than any other type.

However, townhouses and especially apartments - even when equipped with all contemporary comforts and facilities - remain much less popular amongst Emiratis. Regarding townhouses, a $60 \%$ would refuse to live in, primarily due to lack of privacy, while in the case of apartments denial rises to $90 \%$. This is a critical outcome, as the constantly growing list of beneficiaries for the Emirati national housing program, the increasing cost of infrastructure and the sprawling distances of suburbs have sparked skepticism on land management and urban sustainability. It seems that several authorities have started considering changes that could transform the current stereotypical approach on housing and the neighborhood scale. Densification through plot regulations, reduction on the plot sizes, eradication of pedestrian corridors (sikkak) between plots and right of ways narrowing are some of the ideas to start with.

It is important to mention though that this survey provides nothing but a momentary snapshot and what would really affect such a typology shift is the documentation of trends and dynamics. Therefore, more surveys in sufficient time depth are necessary in order to argue in favor of such a demanding transition.

\section{Conclusion}

The conception idea about this survey was to support and expand the observational findings regarding an ongoing shift on housing typologies. This shift emerged in all new cities in the Gulf region during their modernization in the 60s, as the vernacular Arabic house was replaced by the single detached (western) 
villa and the courtyard-centered typology was inverted to a central volume surrounded by setback garden areas. Therefore, this survey achieved its goal in concreting the hypothesis of a cultural paradox, as this typology shift contradicts any contextual (social, cultural, climatic) logic and is fueled solely by the pursuit of a social imaginary.

At the same time, the survey highlighted the fact that Emiratis are not prepared to relinquish any precedent conquest on their private land ownership and housing properties. Therefore, despite the initial efforts of the city authorities to endorse a return to the "fareej" model, such a shift to a less affluent yet more responsive to the context and the sociocultural condition set of architecture typologies would require a more profound, long-term and comprehensive approach. This could include education (through raise of awareness on architecture qualities and sustainability), opening discussion channels between authorities and the beneficiaries for the national housing program regarding land availability and the cost of infrastructure, and a possible set of incentives for the ones that would voluntarily choose to live in new developments that would follow updated policies. Lastly, such a paradigm shift of urban consolidation could also trigger similar changes in nearby countries with similar housing programs and similar social, cultural and climatic conditions.

\section{References}

Abu Dhabi Municipality (2003), Abu Dhabi, Dana of the Gulf. Abu Dhabi: ADM, Planning and Urban Development, Studies and Research section.

Abu Dhabi Urban Planning Council (ADUPC) (2007): Abu Dhabi Plan 2030, Urban Structure Framework Plan.

Al Fahim M.A.J. (2013), From rags to riches; A story of Abu Dhabi. Abu Dhabi: Makarem, 2nd edition

Alawadi K. (2018), Lifescapes beyond bigness. Abu Dhabi: Artifice

Bani Hashim A.M. (2019), Planning Abu Dhabi, an urban history. New York: Routledge

Elsheshtawy Y. (2019), Temporary cities; Resisting transience in Arabia. New York: Routledge

Elsheshtawy Y. (2016), National Emirati Housing Program, UAE Catalog for the Venice Biennale of Architecture 2016

Kyriazis A., Apostolaki M. (2019), "The Abu Dhabi waterfront; Evolution, land-use dynamics and the question of the Open City." In: Mohamed Elkaftangui (ed.), AMPS Proceedings Series 13. Constructing an Urban Future. Abu Dhabi University, UAE. 18 - 19 March (2018). pp. 49-63.

Kyriazis A., Zahid A., Qamar S. (2018), «A cultural paradox and the double shift of the housing typologies in the Arabic Gulf area: Undergraduate research case studies in Abu Dhabi», at the ARCC-EAAE 2018 international conference Proceedings, Volume 2, pp. 88-96

Kyriazis A. (2017), The Morphology of Abu Dhabi's Superblocks: A modernist vision, at: Atiner, 2017: Athens Journal of Architecture, Vol.3, Issue 4. e-ISSN: 2407-9472

Menoret P. (2014), Joyriding in Riyadh. Oil, urbanism and road revolt. New York: Cambridge University Press

Reisz T. (2013), Plans the Earth Swallows: An Interview with Abdulrahman Makhlouf. Portal 9, No 2, at: http://portal9journal.org/articles.aspx?id=92

Stanek L. (2020), Architecture in global socialism. Eastern Europe, West Africa and the Middle East in the cold war. Princeton-Oxford: Princeton University Press 